\title{
Pengaruh Kualitas Pelayanan, Fasilitas Fisik, Dan Kepercayaan Terhadap Kepuasan Konsumen Pada Taman Surgawi Resort dan Spa Di Kabupaten Karangasem
}

\author{
Ni Putu Putri Ayu Wijayanthi' ${ }^{1}$ I Gusti Putu Agung Widyagoca ${ }^{2}$, I Komang Sumerta ${ }^{3}$, \\ Ni Putu Lia Utami ${ }^{4}$ \\ ${ }^{1}$ Institut Teknologi dan Bisnis STIKOM BALI \\ ${ }^{2,3,4}$ Fakultas Ekonomi dan Bisnis Universitas Ngurah Rai Denpasar \\ Email authors: ${ }^{1}$ putri_wijayathi@ stikom-bali.ac.id, ${ }^{2}$ agung.widya10@gmail.com \\ komang.sumerta@unr.ac.id
}

\begin{abstract}
Quality of service, physical facilities and trust are things that affect customer satisfaction. This study aimed to find out how the quality of physical facilities services, and trust can have an influence on consumer satisfaction at Taman Langitwi Resort \& Spa in Karangasem district. This study also aims to determine the quality of service, physical facilities, trust and customer satisfaction at Taman Langitwi Resort \& Spa in Karangasem district. Data analysis using the classic assumption test, multiple linear regression analysis, analysis, determination analysis, partial significance test (t-test) and simultaneous significance test (F-test) results of the study showed that there was a positive and significant effect between service quality, physical facilities and simultaneous trust in customer satisfaction at Taman Langitwi Resort \& Spa in Karangasem Regency.
\end{abstract}

Keywords: Service Quality, Physical Facilities, Trust, Customer Satisfaction.

\section{PENDAHULUAN}

Perkembangan usaha pada era bisnis saat ini telah diwarnai dengan berbagai macam persaingan di segala bidang. Melihat kondisi tersebut menyebabkan pembisnis semakin dituntut untuk mempunyi strategi yang tepat dalam memenuhi target volume penjualan. Mengingat perkembangan teknologi yang makin dinamis, para pembisnis dituntut dengan cepat dan tepat untuk berdintak agar tidak kalah bersaing.Kualitas pelayanan sangat penting dikelola perusahaan dengan baik untuk memenuhi kepuasan konsumen dan ini berlaku juga untuk perusahaan yang bergerak di bidang yang lain.Kualitas adalah keseluruhan ciri serta sifat dari suatu produk atau pelayanan yang berpengaruh pada kemampuannya untuk memuaskan kebutuhan yang dinyatakan atau tersirat (Kotler \& Armstrong, 2018).

Perilaku konsumen dalam melakukan keputusan pembelian semakin kompleks sehingga seorang pemasar harus mampu menguasai segala strategi pemasaran dalam memuaskan konsumennya, salah satunya adalah mengetahui perilaku konsumen dalam memunculkan niat penggunaan dan keputusan pembelian (Sumerta et al., 2019). Selain faktor konsumen, faktor internal pemasar juga sangat penting diperhatikan oleh pengusaha seperti kualitas pelayanan, fasilitas fisik dan kepercayaan (Al Ababneh, 2017; Nurcahyo et al., 2017; Setiawan \& Sayuti, 2017).

Faktor fasilitas juga berpengaruh terhadap kepuasan konsumen karena fasilitas mempunyai peranan penting yang berhubungan dengan persepsi konsumen yang diperoleh 
dari interaksi konsumen dengan fasilitas. Fasilitas adalah segala sesuatu yang disediakan untuk dipakai atau dipergunakan serta dinikmati oleh konsumen (Faeni \& Faeni, 2019; Pitt et al., 2016). Faktor-faktor yang meliputi fasilitas adalah seperti tawaran paket menginap pada hari libur atau hari besar, kelengkapan fasilitas kamar dan kebersihan kamar. Faktor lain yang dapat mempengaruhi tingkat kepuasan konsumen adalah kepercayaan konsumen. Kepercayaan (trust atau belief) merupakan keyakinan bahwa tindakan orang lain atau suatu kelompok konsisten dengan kepercayaan mereka (Junusi, 2020). Dalam hal ini unsur kepercayaan menjadi faktor kunci bagi perusahaan untuk memenangkan persaingan (Junusi, 2020). Kualitas pelayanan yang baik dan fasilitas yang memadai akan memepengaruhi kepuasan konsumen dalam menggunakan jasa yang diberikan holeh Taman Surgawi Resort \& Spa. Apabila konsumen tidak puas terhadap kualitas pelayanan, fasilitas jasa dan kepercayaan yang di berikan, maka konsumen tidak akan kembali menggunakan jasa tersebut.

Tidak kalah pentingnya dalam menciptakan kepuasan konsumen dalam dunia perhotelan adalah kualitas pelayanan, kualitas pelayanan yang baik akan memberikan pengalaman serta kesan yang baik kepada konsumen sehingga mampu menciptakan kepuasan bagi konsumen yang menikmati jasa tersebut, sehingga sangat penting bagi seorang pemasar khususnya dibidang jasa perhotelan untuk memperhatikan kualitas pelayanan dalam mewujudkan kepuasan konsumen (Afthanorhan et al., 2019; Ekaabi et al., 2020; Le et al., 2020; Meesala \& Paul, 2018; Setiawan \& Sayuti, 2017). Berdasarkan hal tersebut maka sebagai pengusaha yang bergerak dibidang perhotelan, yang memberikan pelayanan jasa kepada konsumen, sangat perlu dalam memperhatikan fasilitas fisik, kepercayaan serta kualitas pelayanan dalam menjalankan usahanya sehingga akan terbentuk kepuasan konsumen.

Pada saat ini cukup banyak usaha yang bergerak di bidang jasa perhotelan, salah satunya adalah Taman Surgawi Resort \& Spa.Taman Surgawi Resort \& Spa dibangun dengan arsitektur tradisional dan modern. Wisatawan yang berkunjung ke Taman Surgawi Resort \& Spa dapat menuju ke Istana Air Taman Ujung hanya dengan berjalan kaki. Adapun jumlah kunjungan wisatawan mancanegara maupun domestik yang menginap di Taman SurgawiResort and Spa pada bulan oktober tahun 2018 sampai dengan bulan oktober tahun 2019 dapat dilihat dari Tabel 1 sebagai berikut.

Tabel 1. Jumlah Kunjungan wisatawan yang menginap di Taman Surgawi Resort \& Spa tahun 2018/2019

\begin{tabular}{|l|c|c|}
\hline \multicolumn{1}{|c|}{ Bulan/Tahun } & $\begin{array}{c}\text { Jumlah Wisatawan } \\
\text { (orang) }\end{array}$ & $\begin{array}{c}\text { Pertumbuhan } \\
\mathbf{( \% )}\end{array}$ \\
\hline Oktober 2018 & 73 & $8 \%$ \\
\hline November 2018 & 78 & $16 \%$ \\
\hline Desember 2018 & 89 & $-8 \%$ \\
\hline Januari 2019 & 83 & $-8 \%$ \\
\hline Februari 2019 & 77 & $-16 \%$ \\
\hline Maret 2019 & 66 & $9 \%$ \\
\hline April 2019 & 71 & $-3 \%$ \\
\hline Mei 2019 & 79 & $-2 \%$ \\
\hline Juni 2019 & 68 & $-17 \%$ \\
\hline Juli 2019 & 58 & \\
\hline
\end{tabular}




\begin{tabular}{|l|c|c|}
\hline Agustus 2019 & 55 & $-13 \%$ \\
\hline September 2019 & 50 & $-5 \%$ \\
\hline Oktober 2019 & 49 & $-3 \%$ \\
\hline Grand Total & $\mathbf{8 9 6}$ & \\
\hline
\end{tabular}

Sumber: Laporan kunjungan Taman Surgawi Resort \& Spa (2019)

Berdasarkan Tabel 1 dapat dilihat jumlah wisatawan yang menginap di Taman Surgawi Resort \& Spa pada bulan oktober 2018 sampai dengan bulan oktober 2019 sejumlah 896, terlihat jumlah kunjungan wisatawan yang menginap di Taman Surgawi Resot \& Spa mengalami penurunan yang terjadi enam bulan terakhir. Berdasarkan hasil observasi yang dilakukan pada penelitian ditemukannya beberapa permasalahan yang menyangkut keluhan dari para tamu hotel yang menginap di Taman Surgawi Resort \& Spa.Berdasarkan latar belakang masalah diatas, penulis tertarik untuk melakukan penelitian dengan judul "Pengaruh Kualitas Pelayanan, Fasilitas Fisik, dan Kepercayaan Terhadap Taman Surgawi Resort \& Spa Di Kabupaten Karangasem.

\section{METODE PENELITIAN}

Desain dalam penelitian ini termasuk dalam penelitian kuantitatif .Desain dalam penelitian ini termasuk dalam penelitian kuantitatif, karena penelitian ini disajikan dengan angkaangka.Menurut (Sugiyono, 2015), penelitian kuantitatif dapat diartikan sebagai metode penelitian yang berlandaskan pada filsafat positivisme, digunakan untuk meneliti pada populasi atau sampel tertentu, Pengambilan sampel diambil dengan menggunakan metode purposive random sampling, yaitu teknik pengumpulan sampel penelitian dengan dengan beberapa pertimbangan tertentu yang bertujuan agar data yang diperoleh nantinya bisa lebih representatif. Pertimbangan atau kriteria yang digunakan dalam penentuan sampel ini yaitu responden berusia 17 tahun keatas dan sudah pernah menginap di Taman Surgawi Resort \& Spa. Jumlah populasi dalam penelitian ini adalah semua pengujung yang pernah menginap pada Taman Surgawi Resot \& Spa Kabupaten Karangasem yang berjumlah 896 orang pada tahun 2018 sampai dengan 2019 dengan diambil secara purposive random sampling. Dengan jumlah sample yang digunakan sebanyak 90 orang responden

Teknik pengumpulan data dalam penelitian ini dilakukan melalui observasi wawancara, studi dokumentasi, kuesioner (Sugiyono, 2015). Setiap jawaban kuesioner mempunyai bobot atau skor nilai dengan skala Likert sebagai berikut: SS (Sangat Setuju) = skor 5, S $($ Setuju $)=\operatorname{skor} 4, \mathrm{~N}($ Netral $)=\operatorname{skor} 3$, TS $($ Tidak Setuju $)=\operatorname{skor} 2$ dan STS $($ Sangat Tidak Setuju) = skor 1 . teknik analisis data yang digunakan yaitu terdiri dari, uji validitas dan reliabilitas instrument penelitian, uji asumsi klasik, analisis regresi linier berganda, analisis determinasi, uji t dan uji F. Pengolahan data menggunakan IBM SPSS statistic 24.

\section{HASIL DAN PEMBAHASAN}

\section{Uji Validitas Instrumen Penelitian}

Uji Validitas dilakukan untuk melihat ketepatan dan kecermatan instrument sebagai alat ukur. Hasil Uji Validitas Instrumen dapat dilihat pada Tabel 2 berikut ini: 
Tabel 2 . Hasil Uji Validitas Instrumen PenelitianTabel 3

\begin{tabular}{|c|c|c|c|}
\hline Pernyataan & $\begin{array}{c}\text { Koefisien } \\
\text { Korelasi }\end{array}$ & Standar & Ket. \\
\hline \multicolumn{4}{|c|}{ Kualitas Pelayanan $\left(\mathrm{X}_{1}\right)$} \\
\hline $\mathrm{X} 1.1$ & 0,695 & 0,30 & Valid \\
\hline $\mathrm{X} 1.2$ & 0,707 & 0,30 & Valid \\
\hline $\mathrm{X} 1.3$ & 0,722 & 0,30 & Valid \\
\hline $\mathrm{X} 1.4$ & 0,795 & 0,30 & Valid \\
\hline $\mathrm{X} 1.5$ & 0,677 & 0,30 & Valid \\
\hline \multicolumn{4}{|c|}{ Sumber: Qata diolah, 2020asilitas Fisik $\left(\mathrm{X}_{2}\right)$} \\
\hline P $\mathrm{X} 2.1$ & 0,723 & 0,30 & Valid \\
\hline $\mathrm{X} 2.2$ & 0,733 & 0,30 & Valid \\
\hline $\mathrm{X} 2.3$ & 0,688 & 0,30 & Valid \\
\hline $\mathrm{X} 2.4$ & 0,739 & 0,30 & Valid \\
\hline $\mathrm{X} 2.5$ & 0,721 & 0,30 & Valid \\
\hline \multicolumn{4}{|c|}{ Kepercayaan $\left(\mathrm{X}_{3}\right)$} \\
\hline X3.1 & 0,784 & 0,30 & Valid \\
\hline $\mathrm{X} 3.2$ & 0,809 & 0,30 & Valid \\
\hline X3.3 & 0,756 & 0,30 & Valid \\
\hline $\mathrm{X} 3.4$ & 0,831 & 0,30 & Valid \\
\hline $\mathrm{X} 3.5$ & 0,683 & 0,30 & Valid \\
\hline \multicolumn{4}{|c|}{ Kepuasan Konsumen (Y) } \\
\hline Y1.1 & 0,709 & 0,30 & Valid \\
\hline Y1.2 & 0,687 & 0,30 & Valid \\
\hline Y1.3 & 0,719 & 0,30 & Valid \\
\hline Y1.4 & 0,736 & 0,30 & Valid \\
\hline Sumber: Data diol & $20 \quad 0,765$ & 0,30 & Valid \\
\hline
\end{tabular}

Berdasarkan Tabel 2 tersebut di atas, maka semua variabel nilai koefisien korelasi berada di atas 0,30 , sehingga pertanyaan kuesioner dalam penelitian ini dinyatakan valid.

\section{Uji Reliabilitas Instrumen Penelitian}

Pengujian Reliabilitas atau keandalan instrumen dilakukan untukmengetahui sejauh mana suatu pengukuran dapat memberikan hasil yang tidak berbeda bila dilakukan pengukuran kembali terhadap subjek yang sama. Hasil Uji Reliabilitas Instrumen dapat dilihat pada Tabel 3 berikut ini: 
Tabel 3. Hasil Uji Reliabilitas Instrumen

\begin{tabular}{|l|c|c|c|c|}
\hline \multicolumn{1}{|c|}{ Variabel } & Item & $\begin{array}{c}\text { Cronbach' } \\
\text { s Alpha }\end{array}$ & Standar & Ket. \\
\hline Kualitas Pelayanan & $\mathrm{X}_{1}$ & 0,766 & 0,70 & $\begin{array}{c}\text { Reliabe } \\
1\end{array}$ \\
\hline Fasilitas Fisik & $\mathrm{X}_{2}$ & 0,768 & 0,70 & $\begin{array}{c}\text { Reliabe } \\
1\end{array}$ \\
\hline Kepercayaan & $\mathrm{X}_{3}$ & 0,831 & 0,70 & $\begin{array}{c}\text { Reliabe } \\
1\end{array}$ \\
\hline Kepuasan Konsumen & $\mathrm{Y}$ & 0,769 & 0,70 & $\begin{array}{c}\text { Reliabe } \\
1\end{array}$ \\
\hline
\end{tabular}

Sumber: Data diolah, 2020

Berdasarkan Tabel 3 tersebut di atas, maka semua variabel nilai Cronbach Alpha berada di atas/lebih besar 0,70 sehingga semua instrumen tersebut adalah realibel dan penelitian dapat dilanjutkan.

\section{Uji Asumsi Klasik}

Uji asumsi klasik digunakan untuk mengetahui kelayakan penggunaan model regresi. Dari hasil analisis diperoleh hasil Uji Normalitas seperti pada Tabel 4:

Tabel 4. Uji Normalitas

One-Sample Kolmogorov-Smirnov Test

\begin{tabular}{|c|c|c|}
\hline & & Unstandardized Residual \\
\hline $\begin{array}{l}\mathrm{N} \\
\text { Normal Parameters }{ }^{\mathrm{a}, \mathrm{b}}\end{array}$ & $\begin{array}{l}\text { Mean } \\
\text { Std. Deviation }\end{array}$ & $\begin{array}{r}90 \\
, 0000000 \\
1,80756148\end{array}$ \\
\hline \multirow[t]{2}{*}{ Most Extreme Differences } & Absolute &, 052 \\
\hline & $\begin{array}{l}\text { Positive } \\
\text { Negative }\end{array}$ & $\begin{array}{r}, 052 \\
-, 045 \\
\end{array}$ \\
\hline $\begin{array}{l}\text { Test Statistic } \\
\text { Asymp. Sig. (2-tailed) }\end{array}$ & & $\begin{array}{l}.052 \\
.200\end{array}$ \\
\hline
\end{tabular}

Sumber: Data diolah, 2020

Berdasarkan tabel 4 di atas menunjukkan bahwa nilai Asymp. Sig. (2-tailed) 0,200 lebih besar 0,05. Hal ini berarti seluruh data berdistribusi normal. Selanjutnya, hasil uji multikolinearitas dapat dilihat pada tabel dibawah:

Tabel 5. Uji Multikolinearitas

\section{Coefficientsa}

\begin{tabular}{|c|c|c|c|c|c|c|c|}
\hline \multirow[b]{2}{*}{ Model } & \multicolumn{2}{|c|}{$\begin{array}{c}\text { Unstandardized } \\
\text { Coefficients } \\
\end{array}$} & $\mid \begin{array}{c}\text { Standardize } \\
\mathrm{d} \\
\text { Coefficient } \\
\mathrm{s}\end{array}$ & \multirow[t]{2}{*}{$\mathrm{T}$} & Sig. & \multicolumn{2}{|c|}{$\begin{array}{c}\text { Collinearity } \\
\text { Statistics }\end{array}$} \\
\hline & $\mathrm{B}$ & $\begin{array}{l}\text { Std. } \\
\text { Error }\end{array}$ & Beta & & & $\begin{array}{c}\text { Toleranc } \\
\mathrm{e}\end{array}$ & VIF \\
\hline
\end{tabular}




\begin{tabular}{|l|l|r|r|r|r|r|r|r|}
\hline 1 & (Constant) & 3,048 & 1,286 & & 2,370 &, 020 & & \\
\hline $\begin{array}{l}\text { Kualitas } \\
\text { pelayanan }\end{array}$ &, 302 &, 097 &, 307 & 3,118 &, 002 &, 379 & 2,641 \\
\hline $\begin{array}{l}\text { Fasilitas } \\
\text { Fisik }\end{array}$ &, 226 &, 099 &, 234 & 2,284 &, 025 &, 350 & 2,859 \\
$\begin{array}{l}\text { Kepercayaa } \\
\mathrm{n}\end{array}$ &, 318 &, 086 &, 366 & 3,673 &, 000 &, 371 & 2,696 \\
\hline
\end{tabular}

Sumber: Data diolah, 2020

Berdasarkan Tabel 5 di atas menunjukkan bahwa nilai tolerance untuk kedua variable bebas lebih besar dari 0,1 (10\%) dan nilai VIF lebih kecil dari 10 persen. Dengan demikian, model regresi linier berganda bebas dari multikolinearitas, artinya tidak terdapat korelasi diantara variable bebas dalam model regresi linear berganda tersebut. Hasil uji heteroskedastisitas dapat dilihat pada tabel 6 .

Tabel 6. Uji Heteroskedastisitas

\section{Coefficientsa}

Coefficients $^{\mathrm{a}}$

\begin{tabular}{|c|c|c|c|c|c|}
\hline \multirow[b]{2}{*}{ Model } & \multicolumn{2}{|c|}{$\begin{array}{l}\text { Unstandardized } \\
\text { Coefficients }\end{array}$} & \multirow{2}{*}{$\begin{array}{c}\begin{array}{c}\text { Standardize } \\
\mathrm{d}\end{array} \\
\text { Coefficients } \\
\text { Beta } \\
\end{array}$} & \multirow[t]{2}{*}{$\mathrm{T}$} & \multirow{2}{*}{ Sig. } \\
\hline & B & $\begin{array}{l}\text { Std. } \\
\text { Error }\end{array}$ & & & \\
\hline $1 \quad$ (Constant) & 1.039 & .743 & & 1.399 & .166 \\
\hline $\begin{array}{l}\text { Kualitas } \\
\text { Pelayanan }\end{array}$ & -.009 & .056 & -.028 & -.165 & .869 \\
\hline Fasilitas Fisik & .113 & .057 & .351 & 1.979 & .051 \\
\hline Kepercayaan & -.086 & .050 & -.297 & -1.721 & .089 \\
\hline
\end{tabular}

Sumber: Data diolah, 2020

Berdasarkan hasil uji heteroskedastisitas dapat diketahui nilai signifikan variabel-variabel bebas lebih besar dari pada 0,05 sehingga dapat dikatakan model bebas dari heteroskedastisitas. 


\section{Analisis Regresi Linier Berganda}

Hasil analisisnya dapat dilihat pada Tabel 7 sebagai berikut:

Tabel 7. Hasil Analisis Regresi Linier Berganda

\section{Coefficients ${ }^{\mathrm{a}}$}

\begin{tabular}{|c|c|c|c|c|c|c|}
\hline \multirow{2}{*}{\multicolumn{2}{|c|}{ Model }} & \multicolumn{2}{|c|}{$\begin{array}{c}\text { Unstandardized } \\
\text { Coefficients }\end{array}$} & $\begin{array}{c}\text { Standardiz } \\
\text { ed } \\
\text { Coefficient } \\
\text { s } \\
\end{array}$ & \multirow[t]{2}{*}{$\mathrm{t}$} & \multirow[t]{2}{*}{ Sig. } \\
\hline & & B & $\begin{array}{l}\text { Std. } \\
\text { Error }\end{array}$ & & & \\
\hline \multirow[t]{4}{*}{1} & (Constant) & 3.048 & 1.286 & & 2.370 & .020 \\
\hline & $\begin{array}{l}\text { Kualitas } \\
\text { Pelayanan }\end{array}$ & .302 & .097 & .307 & 3.118 & .002 \\
\hline & Fasilitas Fisik & .226 & .099 & .234 & 2.284 & .025 \\
\hline & Kepercayaan & .318 & .086 & .366 & 3.673 & .000 \\
\hline
\end{tabular}

Sumber: Data diolah, 2020

Berdasarkan nilai-nilai pada Tabel 7 maka persamaan regresi linier berganda akan menjad: $\mathrm{Y}=3,048+0,302 \mathrm{X} 1+0,226 \mathrm{X} 2+0,318 \mathrm{X} 3$

Berdasarkan persamaan tersebut, maka pengaruh kualitas pelayanan, fasilitas fisik dan kepercayaan terhadap kepuasan konsumen pada Taman Surgawi Resort \& Spa di Kabupaten Karangasem dapat diartikan sebagai berikut :

a. Koefisien konstan a sebesar 3,048. Berarti apabila kualitas pelayanan tidak ditingkatkan, fasilitas fisik tidak ditambah, dan kepercayaan konsumen tidak meningkat, maka kepuasan konsumen pada Taman Surgawi Resort \& Spa di Kabupaten Karangasem akan tetap seperti sedia kala.

b. Koefisienregresi X1sebesar 0,302. Berarti terdapat pengaruh positif dan signifikan antara variable kualitas pelayanan terhadap kepuasan konsumen. Koefisien bertanda positif, berarti bahwa semakin baik kualitas pelayanan, maka semakin meningkat kepuasan konsumen pada Taman Surgawi Resort \& Spa di Kabupaten Karangasem (dengan asumsi variable independen lainnya konstan).

c. Koefisienregresi X2sebesar 0,226. Berarti terdapat pengaruh positif dan signifikan antara variable fasilitas fisik terhadap kepuasan konsumen. Koefisien bertanda positif, berarti bahwa semakin lengkap fasilitas, maka semakin meningkat keputusan menginap wistawan pada Taman Surgawi Resort \& Spa di Kabupaten Karangasem (dengan asumsi variable independen lainnya konstan).

d. Koefisienregresi X3sebesar 0,318. Berarti terdapat pengaruh positif dan signifikan antara variable kepercayaan terhadap kepuasan konsumen. Koefisien bertanda positif, berarti bahwa semakin tinggi kepercayaan dari konsumen, maka semakin meningkat kepuasan konsumen pada Taman Surgawi Resort \& Spa di Kabupaten Karangasem (dengan asumsi variable independen lainnya konstan). 


\section{Analisis Koefisien Determinasi}

Tabel 8. Hasil Analisis Determinasi Model Summaryb

\begin{tabular}{|l|r|r|r|r|}
\hline Model & R & R Square & $\begin{array}{c}\text { Adjusted R } \\
\text { Square }\end{array}$ & $\begin{array}{c}\text { Std. Error of the } \\
\text { Estimate }\end{array}$ \\
\hline 1 & $.827^{\mathrm{a}}$ & .684 & .673 & 1.83882 \\
\hline
\end{tabular}

Sumber :Data diolah, 2020

Berdasarkan hasil tabel di atas diperoleh koefisien determinasi 68,4\% berarti kualitas pelayanan, fasilitas fisik dan kepercayaan terhadap kepuasan konsumen pada Taman Surgawi Resort \& Spa di Kabupaten Karangasem mempunyai hubungan sebesar 68,4\%, sedang sisanya $100 \%-68,4 \%=31,2 \%$ dipengaruhi faktor-faktor lain yang tidak dibahas dalam penelitian ini.

\section{Uji Segnifikansi Simultan (t-tes)}

Hasil analisis uji t-tesdapat dilihat pada Tabel 9 sebagai berikut:

Tabel 9. Hasil Analisis Uji Segnifikansi Parsial (t-tes)

Coefficients $^{\mathrm{a}}$

\begin{tabular}{|ll|r|r|r|r|r|}
\hline \multirow{2}{*}{ Model } & \multicolumn{2}{|c|}{$\begin{array}{c}\text { Unstandardized } \\
\text { Coefficients }\end{array}$} & $\begin{array}{c}\text { Standardized } \\
\text { Coefficients }\end{array}$ & \multirow{2}{*}{$\mathrm{T}$} & \multirow{2}{*}{ Sig. } \\
\cline { 2 - 4 } & \multicolumn{1}{|c|}{ B } & Std. Error & \multicolumn{1}{c|}{ Beta } & & \\
\hline (Constant) & 3.048 & 1.286 & & 2.370 & .020 \\
& Kualitas Pelayanan & .302 & .097 & .307 & 3.118 & .002 \\
\cline { 2 - 6 } & Fasilitas Fisik & .226 & .099 & .234 & 2.284 & .025 \\
& Kepercayaan & .318 & .086 & .366 & 3.673 & .000 \\
\hline
\end{tabular}

Sumber: Data diolah, 2020

Hasil uji statistik diperoleh nilai Berdasarkan keseluruhan hasil pengujian di atas ditemukan bahwa signifikansi seluruh variable bebas secara parsial dibawah 0,05 yang berarti seluruh variable bebas dinyatakan berpengaruh signifikan secara parsial terhadap kepuasan konsumen.

\section{Uji Segnifikansi Simultan (F)}

Hasil analisis uji Fdapat dilihat pada Tabel 10 sebagai berikut:

Tabel 10. Hasil Analisis Uji F ANOVA

\begin{tabular}{|c|c|c|c|c|c|}
\hline $\begin{array}{l}\text { Hasil Analisis Uji } \\
\text { FModel }\end{array}$ & $\begin{array}{l}\text { Sum of } \\
\text { Squares }\end{array}$ & Df & $\begin{array}{l}\text { Mean } \\
\text { Square }\end{array}$ & $\mathrm{F}$ & Sig. \\
\hline $\begin{array}{ll}1 & \text { Regressio } \\
& \mathrm{n} \\
& \text { Residual } \\
& \text { Total } \\
\end{array}$ & $\begin{array}{l}628.201 \\
290.788 \\
918.989 \\
\end{array}$ & $\begin{array}{r}3 \\
86 \\
89\end{array}$ & $\begin{array}{r}209.400 \\
3.381\end{array}$ & 61.930 & $.000^{\mathrm{b}}$ \\
\hline
\end{tabular}

Sumber: Data diolah, 2020 
Berdasarkan keseluruhan hasil pengujian di atas, dengan tingkat signifikansi 0,000 lebih kecil dari 0,05 (5\%) serta diperoleh nilai F-hitung sebesar 61,930 dan nilai F-tabel sebesar 2,76, sehingga kalau disbanding kanmaka nilai F-hitung lebih besar dari nilai F-tabel dan F-hitung berada pada daerah penolakan Ho. Oleh karenaitu, Ho ditolak dan Ha diterima. Ini berarti bahwa kualitas pelayanan, fasilitas fisik dan kepercayaan secara simultan berpengaruh positif dan signifikan terhadap kepuasan konsumen pada Taman Surgawi Resort \& Spa di Kabupaten Karangasem.

\section{KESIMPULAN DAN SARAN}

Berdasarkan uraian pada bab-bab sebelumnya, maka simpulan yang dapat ditarik berkaitan dengan pengaruh kualitas pelayanan, fasilitas fisik dan kepercayaan terhadap kepuasan konsumen pada Taman Surgawi Resort \& Spa di Kabupaten Karangasem adalah sebagai berikut :

1. Kualitas pelayanan berpengaruh positif dan signifikan secara parsial terhadap kepuasan konsumen. Nilai t-hitung variabel kualitas pelayanan adalah 3,118 lebih besar dari nilai t-tabel 1,671. Ini berarti kualitas pelayanan berpengaruh positif dan signifikan terhadap kepuasan konsumen. Hal ini mengindikasikan bahwa semakin tinggi kualitas pelayanan yang diberikan oleh pelaku usaha perhotelan khususnya taman surgawi resort and spa di kabupaten Karangasem maka akan meningkatkan pula kepuasan konsumen dalam menggunakan jasa tersebut. (Afthanorhan et al., 2019; Al Ababneh, 2017; Ekaabi et al., 2020; Lee et al., 2018; Meesala \& Paul, 2018)

2. Fasilitas fisik berpengaruh positif dan signifikan secara parsial terhadap kepuasan konsumen. Nilai t-hitung variabel fasilitas fisik adalah 2,284 lebih besar dari nilai ttabel 1,671. Ini berarti fasilitas fisik berpengaruh positif dan signifikan terhadap kepuasan konsumen. Hasil penelitian ini menunjukkan bahwa fasilitas fisik perusahaan jasa perhotelan memberikan kontribusi yang positif dan signifikan terhadap kepuasan konsumen, semakin baik fasilitas fisik yang diberikan oleh pengelola jasa perhotelan, maka semakin tinggi pula tingkat kepuasan konsumen dalam menggunakan jasa tersebut. Sehingga fasilitas fisik berpengaruh terhadap kepuasan konsumen. (Greenwell et al., 2002; Hui et al., 2013; Nurcahyo et al., 2017; Sutomo \& Baktiono, 2019)

3. Kepercayaan berpengaruh positif dan signifikan secara parsial terhadap kepuasan konsumen. Nilai t-hitung variabel kepercayaan adalah 3,673 lebih besar dari nilai ttabel 1,671. Ini berarti kepercayaan berpengaruh positif dan signifikan terhadap kepuasan konsumen. Kepercayaan merupakan salah satu bagian terpenting dalam membentuk kepuasan konsumen, semakin tinggi tingkat kepercayaan konsumen terhadap suatu produk maupun jasa, maka akan semakin tinggi pula tingkat kepuasan konsumen terhadap produk atau jasa tersebut, hasil penelitian serupa juga telah ditemukan penelitian sebelumnya, sehingga hasil penelitian ini relevant dengan penelitian-penelitian sebelumnya. (Anwar et al., 2020; Damia Zamry \& Md Nayan, 2020; Rimawan et al., 2017; Setiawan \& Sayuti, 2017; Tran \& Vu, 2019)

4. Secara simultan kualitas pelayanan, fasilitas fisik dan kepercayaan berpengaruh positif dan signifikan terhadap kepuasan konsumen. Berdasarkan hasil analisis didapat bahwa nilai F-hitung 61,930 lebih besar dari nilai F-tabel 2,76. Ini berarti kualitas pelayanan, fasilitas fisik dan kepercayaan secara simultan berpengaruh positif dan signifikan 
terhadap kepuasan konsumen. (Mahardika et al., 2018; Sinaga et al., 2020; Sumantri \& Nugrahanto, 2018; Susanti \& Wahyuni, 2017)

\section{Saran}

Berdasarkan uraian kesimpulan tersebut diatas, maka saran-saran yang dapat disampaikan berkaitan dengan pengaruh kualitas pelayanan, fasilitas fisik dan kepercayaan terhadap kepuasan konsumen pada Taman Surgawi Resort \& Spa di Kabupaten Karangasem adalah sebagai berikut :

1. Mengingat empati (emphaty) merupakan indikator yang memiliki rata-rata skor terendah dari variable kualitas pelayanan, maka sebaiknya pihak Taman Surgawi Resort \& Spa di Kabupaten Karangasem meningkatkan empatinya kepada konsumen (wisatawan) dengan cara meningkatkan perhatian kepada wisatawan yang menginap. Contohnya cepat dalam mengatasi atau merespon keluhan konsumen.

2. Mengingat pertimbangan/perencanaan special merupakan indikator dari fasilitas fisik yang memperoleh skor terendah, maka sebaiknya Taman Surgawi Resort \& Spa di Kabupaten Karangasem melaksanakan perencanaan yang special seperti kegiatan special bagi konsumen di hari special wisatawan bersangkutan.

3. Pelayanan cepat merupakan indikator dari kepercayaan yang memperoleh rata-rata skor terendah, maka Taman Surgawi Resort \& Spa di Kabupaten Karangasem menginstruksikan kepada para pegawainya agar lebih cepat dalam melayani wisatawan baik itu pelayanan pembersihan kamar, pelayanan Spa maupun pelayanan makanan dan minuman.

4. Fasilitas sesuai dengan harga merupakan indikator dari kepuasan konsumen yang memperoleh rata-rata skor terendah, maka Taman Surgawi Resort \& Spa di Kabupaten Karangasem memperbaharui fasilitas-fasilitas yang sudah lama dengan fasilitas yang lebih menarik, agar lebih sesuai dengan harga yang diterapkan.

\section{DAFTAR PUSTAKA}

Afthanorhan, A., Awang, Z., Rashid, N., Foziah, H., \& Ghazali, P. L. (2019). Assessing the effects of service quality on customer satisfaction. Management Science Letters, 9(1). https://doi.org/10.5267/j.msl.2018.11.004

Al Ababneh, M. M. (2017). Service Quality in the Hospitality Industry. Journal of Tourism \& Hospitality, 06(01). https://doi.org/10.4172/2167-0269.1000e133

Anwar, Y., Ferine, K. F., \& Sihombing, N. S. (2020). Competency of human resources and customer trust on customer satisfaction and its consequence on customer retention in the hospitality industry north sumatra. Journal of Environmental Management and Tourism, 11(6). https://doi.org/10.14505/jemt.v11.6(46).22

Damia Zamry, A., \& Md Nayan, S. (2020). What Is the Relationship Between Trust and Customer Satisfaction? Journal of Undergraduate Social Science and Technology, 2(2).

Ekaabi, M., Khalid, K., \& Davidson, R. (2020). The service quality and satisfaction of smart policing in the UAE. Cogent Business and Management, 7(1). https://doi.org/10.1080/23311975.2020.1751904

Faeni, R. P., \& Faeni, D. P. (2019). Effect of price, promotion, and facilities to customer satisfaction in using the service event management. International Journal of Recent Technology and Engineering, 8(2 Special Issue 4). 
https://doi.org/10.35940/ijrte.B1163.0782S419

Greenwell, T. C., Fink, J. S., \& Pastore, D. L. (2002). Assessing the Influence of the Physical Sports Facility on Customer Satisfaction within the Context of the Service Experience. Sport Management Review, 5(2). https://doi.org/10.1016/S1441-3523(02)70064-8

Hui, E. C. m., Zhang, P., \& Zheng, X. (2013). Facilities management service and customer satisfaction in shopping mall sector. Facilities, 31. https://doi.org/10.1108/02632771311307070

Junusi, R. El. (2020). Digital Marketing During the Pandemic Period; A Study of Islamic Perspective. Journal of Digital Marketing and Halal Industry, 2(1). https://doi.org/10.21580/jdmhi.2020.2.1.5717

Kotler, P., \& Armstrong, G. (2018). Kotler \&amp; Armstrong, Principles of Marketing | Pearson. In Pearson.

Le, D. N., Nguyen, H. T., \& Hoang Truong, P. (2020). Port logistics service quality and customer satisfaction: Empirical evidence from Vietnam. Asian Journal of Shipping and Logistics, 36(2). https://doi.org/10.1016/j.ajsl.2019.10.003

Lee, S. U., Park, G., \& Kang, J. (2018). The double-edged effects of the corporate venture capital unit's structural autonomy on corporate investors' explorative and exploitative innovation. Journal of Business https://doi.org/10.1016/j.jbusres.2018.01.049

Mahardika, I. M. N. O., SE., MM, D. I. N. S., \& SE., MM, D. I. N. L. (2018). Determination Loyalty Based on Service Quality, Customer Satisfaction and Trust at Pt. Bpr Bukit Tanjung Badung. International Journal of Contemporary Research and Review, 9(02). https://doi.org/10.15520/ijcrr/2018/9/02/424

Meesala, A., \& Paul, J. (2018). Service quality, consumer satisfaction and loyalty in hospitals: Thinking for the future. Journal of Retailing and Consumer Services, 40. https://doi.org/10.1016/j.jretconser.2016.10.011

Nurcahyo, R., Fitriyani, A., \& Hudda, I. N. (2017). The Influence of Facility and Service Quality towards Customer Satisfaction and Its Impact on Customer Loyalty in Borobudur Hotel in Jakarta. Binus Business Review, 8(1). https://doi.org/10.21512/bbr.v8i1.1790

Pitt, M., Chotipanich, S., Issarasak, S., Mulholland, K., \& Panupattanapong, P. (2016). An examination of facility management, customer satisfaction and service relationship in the Bangkok healthcare system. In Indoor and Built Environment (Vol. 25, Issue 3). https://doi.org/10.1177/1420326X14555420

Rimawan, E., Mustofa, A., \& Mulyanto, A. D. (2017). The Influence of Product Quality, Service Quality and Trust on Customer Satisfaction and Its Impact on Customer Loyalty (Case Study PT ABC Tbk). International Journal of Scientific \& Engineering Research, 8(7).

Setiawan, H., \& Sayuti, A. J. (2017). Effects of Service Quality, Customer Trust and Corporate Image on Customer Satisfaction and Loyalty: An Assessment of Travel Agencies Customer in South Sumatra Indonesia. IOSR Journal of Business and Management, 19(05). https://doi.org/10.9790/487x-1905033140

Sinaga, O. S., Putri, D. E., Banjarnahor, A. R., Halim, F., Halim, F., \& Sudirman, A. (2020). Mampukah Citra Merek, Fasilitas dan Kepercayaan Meningkatkan Kepuasan Pengunjung Taman Hewan Kota Pematangsiantar. Inovbiz: Jurnal Inovasi Bisnis, 8(2). https://doi.org/10.35314/inovbiz.v8i2.1447 
Sugiyono. (2015). Sugiyono, Metode Penelitian dan Pengembangan Pendekatan Kualitatif, Kuantitatif, dan R\&D , (Bandung: Alfabeta, 2015), 407 1. Metode Penelitian Dan Pengembangan Pendekatan Kualitatif, Kuantitatif, Dan R\&D.

Sumantri, A. S., \& Nugrahanto, R. (2018). PENGARUH JASA PELAYANAN FREIGHT FORWARDING TERHADAP KEPUASAN PELANGGAN. JURNAL SAINS DAN TEKNOLOGI MARITIM, 1. https://doi.org/10.33556/jstm.v0i1.186

Sumerta, I. K., Widyagoca, I. G. P. A., \& Meryawan, I. W. (2019). Online consumer behavior on using social media on E-commerce, based on the AISAS model approach. Case study; Bukalapak, Tokopedia and Blili.com. International Journal of Advanced Trends in Computer Science and Engineering, 8(1.5 Special Issue). https://doi.org/10.30534/ijatcse/2019/4281.52019

Susanti, D., \& Wahyuni, D. U. (2017). Pengaruh Faktor Kepercayaan, Kualitas Layanan, Dan Fasilitas Terhadap Kepuasan Pelanggan Kereta Api. Jurnal Ilmu Dan Riset Manajemen, $6(5)$.

Sutomo, H. A. O., \& Baktiono, E. R. A. (2019). The influence of prices, facilities, and promotions on customer satisfaction at Grand Darmo Suite Surabaya. Journal of World Conference (JWC), 1(1). https://doi.org/10.29138/prd.v1i1.49

Tran, V. D., \& Vu, Q. H. (2019). Inspecting the relationship among e-service quality, e-trust, e-customer satisfaction and behavioral intentions of online shopping customers. Global Business and Finance Review, 24(3). https://doi.org/10.17549/gbfr.2019.24.3.29 